\title{
OS DOMÍNIOS DE APRENDIZAGEM E O PAPEL DO PROFESSOR
}

\author{
Mára Lúcia Fernandes Carneiro* \\ Cleci Maraschin ${ }^{* *}$ \\ Liane Margarida R. Tarouco ${ }^{* * *}$
}

\begin{abstract}
Resumo: A constituição de domínios de aprendizagem, sob a ótica de Maturana, passa pela construção de redes de conversação. A observação de vários cursos de línguas a distância, ministrados por diferentes professores mas com os mesmos recursos tecnológicos, mostra que essas redes estabelecem-se a partir de ações e propostas dos professores. Assim, não basta disponibilizar para os alunos os recursos como o bate-papo, o correio ou um fórum de discussão, mas é imprescindível que o professor proponha atividades relacionadas a estes recursos e que tenham significado para os alunos.
\end{abstract}

Palavras-chave: educação a distância, comunicação, acoplamento tecnológico

\begin{abstract}
The cognitive domain constitution, under a Maturana's point of view, implies in the construction of a conversation network. The observation of several distance language courses, had taught by different teachers but with the same technological resources, shows that these networks are build from teacher actions and challenges. So, we don't have only to provide access to chat, mail or discussion lists for the students. The teachers have to suggest activities related with this communication technologies and they have to be meaningful to students.
\end{abstract}

Key-words: distance learning, communication, technological coupling

\section{CRIANDO O CENÁRIO}

A Universidade Estadual do Rio Grande do Sul (UERGS), criada em julho de 2001, iniciou suas atividades em março de 2002. Sua proposta diferenciada de ensino e aprendizagem, envolvendo intensamente a tecnologia, proporcionou a instalação de equipamentos de videoconferência e a conexão à Internet das dezoito Unidades da Universidade, distribuídas ao longo do Estado. Isto permitiu que fossem oferecidos os primeiros cursos a distância para preparar os professores no uso do ambiente virtual de aprendizagem adotado, o TelEduc (ROCHA, 2002). No segundo semestre de 2002 iniciou-se o projeto piloto do Laboratório de Língua a Distância (LabLad), com a implantação dos cursos de línguas italiana e inglesa a distância.

Ao longo de 2003 estas experiências foram intensificadas, através do desenvolvimento de cursos de formação de funcionários e professores, bem como novas turmas de cursos de línguas. Um total de 26 cursos foram oferecidos. Desses, quatorze tiveram como objetivo a formação dos professores e agentes técnicos da UERGS, além dos professores dos institutos de idiomas e técnicos da Companhia de Processamento de Dados do RGS (PROCERGS). Os nove cursos restantes foram ministrados pelos professores de idiomas e os técnicos da PROCERGS aos professores, alunos e

\footnotetext{
* Engenheira Química, Doutora em Informática na Educação (PGIE/UFRGS), UERGS/Informática - Coordenadora da Área de Informática na Educação, mara@uergs.edu.br

*** Psicóloga, Doutora em Educação (UFRGS), Professora do Instituto de Psicologia-UFRGS. Professora Adjunta do

Instituto de Psicologia. Coordenadora do Programa de Pesquisa Cognição e Novas Tecnologias da UFRGS.

**** Professora Titular, Doutora em Engenharia Elétrica (USP), Diretora do CINTED-UFRGS, liane@ penta.ufrgs.br

V. 2 № 1 , Março, 2004
} 
funcionários, com o acompanhamento da Área de Informática. A seguir, apresentamos algumas considerações resultantes destas experiências.

\subsection{Experiência do Laboratório de Línguas a Distância}

O Laboratório de Línguas a Distância foi criado com o objetivo de oferecer cursos de línguas para todas as unidades da universidade, utilizando-se dos recursos para suporte à comunicação e interação proporcionados pela infra-estrutura da UERGS. Ao mesmo tempo, permitiu que a equipe envolvida pudesse compartilhar experiências e explorar melhor os recursos disponíveis.
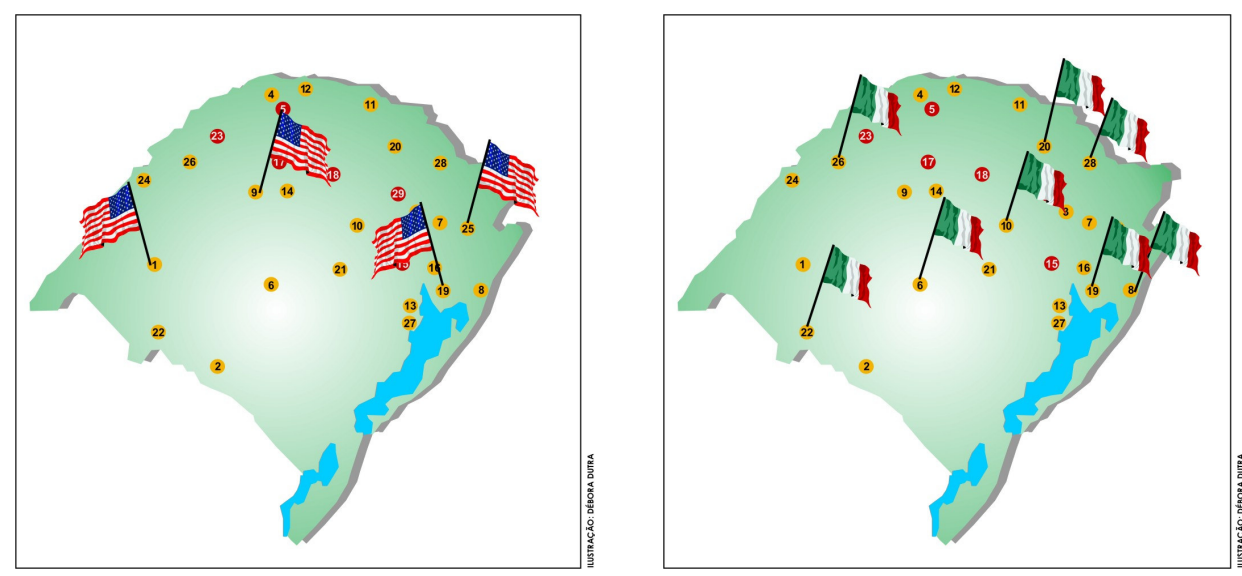

Figura 1 - Unidades atendidas pelos cursos do LabLad - inglês e italiano

De outubro de 2002, quando iniciou o projeto piloto com os cursos de inglês e italiano, até o final de 2003, foram realizados nove cursos (italiano, francês e alemão), envolvendo, aproximadamente, 170 alunos, professores e funcionários. Todas as Unidades conectadas estiveram envolvidas nestes cursos, conforme mostram as Figuras 1 e 2 .
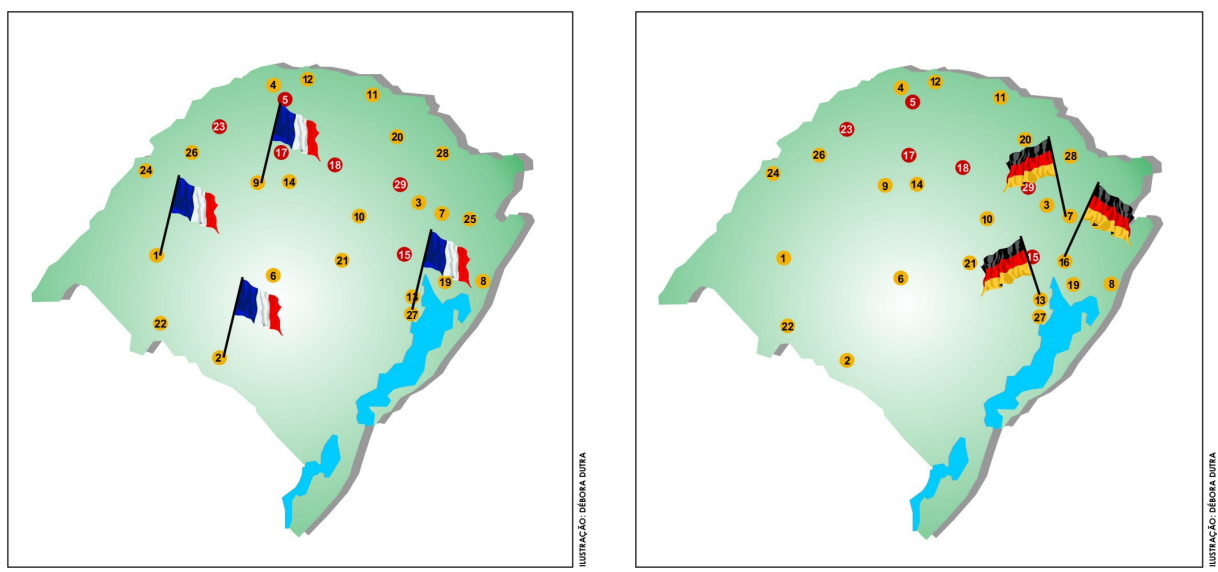

Figura 2 - Unidades atendidas pelos cursos do LabLad - francês e alemão

Nestes cursos participaram alunos, agentes administrativos e professores de 17 Unidades, além dos funcionários da Reitoria, permitindo que a experiência ampliasse tivesse uma abrangência mais significativa.

Para que estes cursos fossem oferecidos utilizando-se dos recursos tecnológicos disponíveis na UERGS, foram oferecidos cursos de formação aos professores dos institutos de línguas conveniados (Aliança Francesa, Instituto Goethe, Associação 
Cultural Italiana do RGS). Estes cursos envolveram o aprendizado do uso do ambiente virtual de aprendizagem (TelEduc) e orientação para a criação dos cursos de línguas neste ambiente, bem como os fundamentos sobre o sistema de videoconferência para apoio às aulas em tempo real.

\subsection{Formação de professores}

Os cursos para os professores tiveram como objetivo principal a divulgação e formação no uso do ambiente TelEduc, tanto como alunos quanto exercendo o papel de professores no ambiente.

Foram então oferecidos dois tipos de cursos. O curso Explorando o ambiente TelEduc apresenta o ambiente virtual de aprendizagem TelEduc e seus recursos, enquanto no curso Formando formadores os professores utilizam o ambiente TelEduc para construir e oferecer um curso piloto.

\subsection{Formação dos agentes administrativos}

A formação dos agentes administrativos envolveu o oferecimento de curso específico sobre o sistema de videoconferência (Videoconferência como suporte a EAD), onde os participantes puderam conhecer o sistema adotado, os cuidados de manutenção, montagem e desmontagem e seu uso como apoio didático às atividades da universidade. Deste curso, participaram dois representantes de cada Unidade.

Também foi organizada com a PROCERGS uma versão do curso básico a distância sobre o Sistema de Protocolo Integrado (SPI). Este curso envolveu inicialmente o oferecimento de curso específico para os técnicos da PROCERGS, que aprenderam a usar os recursos tecnológicos disponíveis para apoiar um curso desta natureza. A partir deste curso, passou-se à adaptação do material adotado nos cursos presenciais para ser utilizado em curso a distância. O curso foi oferecido no segundo semestre de 2003 para todos os agentes administrativos das Unidades do Interior, Porto Alegre e agentes e professores que trabalham na Reitoria, eliminando viagens e afastamento de seus postos de trabalho.

\subsection{Cursos utilizando o ambiente TelEduc pelos professores da UERGS}

A partir da formação no uso do TelEduc, diversos professores passaram a utilizar o ambiente virtual como espaço para publicação de seus materiais de aula e interação com os seus alunos. Ao longo de 2002/03 foram criados 70 cursos vinculados às diversas áreas de ensino (Gestão Ambiental, Saúde Pública, Área da Vida, Educação e Desenvolvimento de Sistemas de Produção Industrial) e a Área de Informática acompanhou e orientou os professores durante a realização destes cursos.

\section{CRIANDO DOMÍNIOS DE APRENDIZAGEM}

Para Maturana, o ser vivo vive imerso em seu meio e, quando o percebe (atuando como um observador), deslancha mecanismos internos que permitem a reinterpretação e recriação das informações assimiladas. Para este autor, as interações recorrentes que se estabelecem entre ser vivo e meio externo promovem transformações em ambos, gerando o que ele chama de acoplamento estrutural (MATURANA, 2001). 
Maturana e Varela (2001) analisam os fenômenos sociais a partir das interações entre organismos. Na visão destes pesquisadores, do ponto de vista da dinâmica interna de um organismo, o outro representa uma fonte de perturbações que não podem ser distinguidas daquelas que vem do meio. No entanto, ao longo de sua ontogenia, é possível que estas interações tornem-se recorrentes, fazendo com que ocorra um acoplamento estrutural tal que permita a manutenção da individualidade dos organismos que interagem.

Estes acoplamentos são denominados de "terceira ordem" e geram modelos de interação que permitem constituir novos domínios de interação que os indivíduos isolados não poderiam produzir. Neste devir, cada indivíduo está constantemente ajustando sua posição na rede de interações formadas pelo grupo, segundo sua dinâmica particular, resultando um acoplamento estrutural grupal (CARNEIRO, 2003).

Maturana e Varela (2001) consideram a comunicação como o desencadeamento mútuo de comportamentos coordenados que observamos em um grupo e que eles denominam de acoplamento social.

No caso de ambientes que utilizam intensamente recursos tecnológicos para suportar a interação e comunicação, podemos identificar o estabelecimento de acoplamentos tecnológicos. Especificamente nos ambientes de aprendizagem a distância, professores e alunos interagem constante e recursivamente através da tecnologia, seja esta um ambiente virtual de aprendizagem via Internet ou um sistema sofisticado de videoconferência (ou ambos).

Em Carneiro (2003) discutiu-se como o acoplamento entre alunos, professores e tecnologia produz outros modos de construir o domínio de ações coletivas do conversar ou "dar voltas com" no sentido adotado por Maturana. Para este cientista, a palavra conversar vem da união de duas raízes latinas: cum, que quer dizer "com", e versare que quer dizer "dar voltas com" o outro (MATURANA, 2001, p. 167). Desta forma, nenhum gesto, conduta ou postura particular constitui por si só um elemento da linguagem, mas é parte dela somente na medida em que pertence a um fluir recursivo de coordenações consensuais de conduta.

Esse domínio de ações compartilhadas e coordenadas (conceitos, teorias, exercícios, etc.) poderia ser pensado como um local, onde cada participante precisa realizar um esforço de construção de uma consensualidade com o outro e poder então compreender o sentido das mensagens dos outros em seu próprio território de experiências já vivenciadas.

E, como afirmam Maturana e Varela (2001), o conhecimento não é passivo, mas construído pelo ser vivo em suas interações com o mundo. E são as interações que se estabelecem nos domínios de aprendizagem que se constituem nos cursos a distância e os acoplamentos tecnológicos daí decorrentes que servem de base para a análise que segue.

\section{ANALISANDO ALGUNS DOMÍNIOS DE APRENDIZAGEM}

A análise dos cursos inicialmente oferecidos através do Laboratório de Línguas a Distância demonstrou que havia uma grande centração do processo comunicativo na figura do professor (CARNEIRO e MARASCHIN, 2003). Os professores envolvidos justificavam este fato afirmando que os alunos eram iniciantes na língua e, por este motivo, sentiam-se inseguros em escrever e interagir durante o curso, utilizando recursos textuais como o correio eletrônico e o bate-papo. 
Ao longo de 2003, um dos cursos (denominado aqui de Curso de Línguas 1) teve continuidade com o mesmo professor, permitindo que se acompanhasse o processo comunicativo ao longo de mais dois semestres, avaliando a validade da justificativa inicialmente apresentada.

A representação das interações via correio eletrônico mostrou que o processo comunicativo continuou centrado no professor no segundo semestre do curso (Figura 3a). A análise das mensagens mostra que o correio foi essencialmente utilizado para o envio das correções dos trabalhos propostos, não oferecendo nenhuma oportunidade de comunicação entre os alunos. Esta ocorria somente nas aulas em tempo real, via videoconferência, reproduzindo o modelo utilizado pelo professor em suas aulas presenciais.

Já no terceiro semestre do curso, o professor propôs uma atividade extraclasse (a correção dos exercícios pelos colegas) utilizando o correio eletrônico. O mapa das interações neste período parece indicar a constituição de um novo domínio social, que poderia constituir-se como um domínio de aprendizagem (Figura 3b).

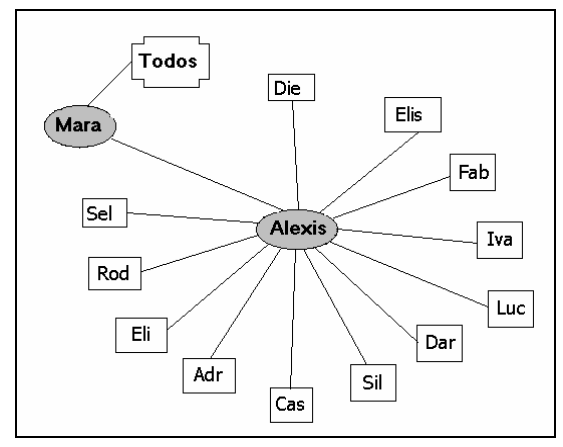

(a)

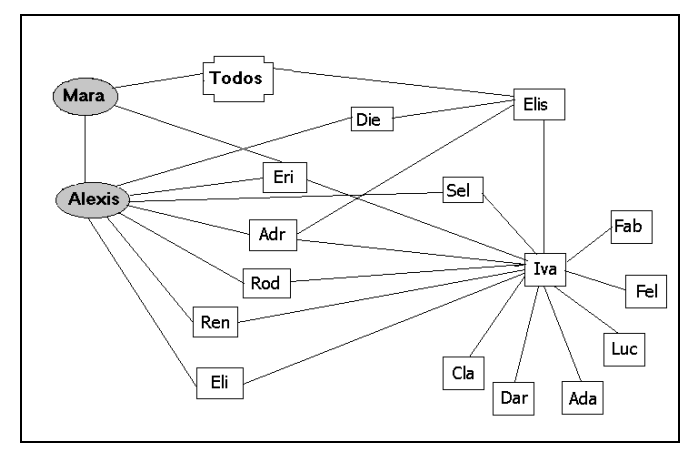

(b)

Figura 3 - Mapas das interações no Curso 1

$\begin{array}{ll}\text { (a) segundo semestre } & \text { (b) terceiro semestre }\end{array}$

Legenda: elipses sombreadas - professor; retângulos - alunos

No entanto, uma análise mais cuidadosa a partir da relação entre o número de mensagens enviadas durante o período de observação e o seu conteúdo nos apresenta uma outra realidade. A Figura 4 apresenta o gráfico que relaciona o número de mensagens enviadas durante a realização do Curso de Línguas 1 (nível 3), tanto pelo professor (ou formador, como o TelEduc designa este papel) quanto pelos alunos. 


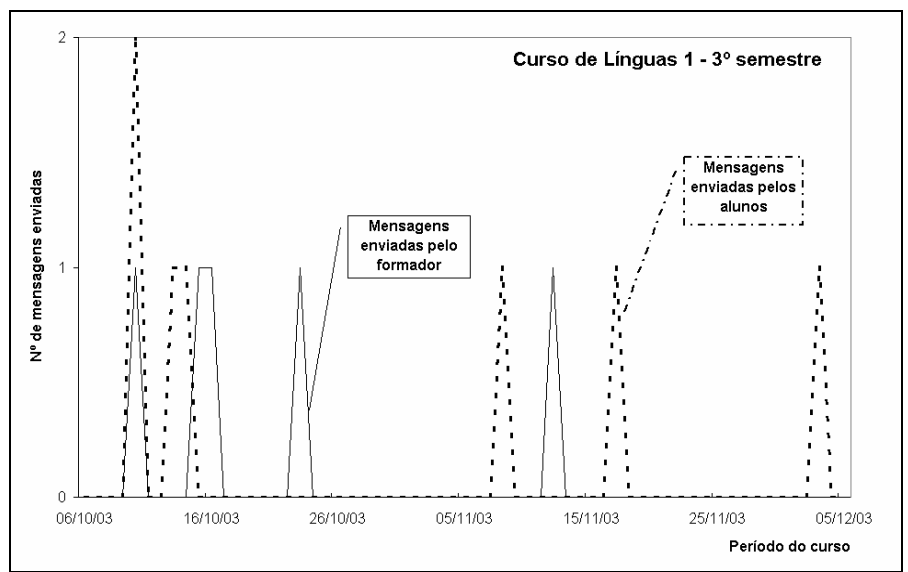

Figura 4 - Curso de Línguas 1 - mensagens trocadas entre formador e alunos

Enquanto o mapa das interações indicava um aumento no número de interações no terceiro semestre do curso, o gráfico nos mostra que o número de mensagens enviadas durante o período de análise nunca ultrapassou duas mensagens por dia. Isto parece indicar que o professor continuou considerando a tecnologia disponível como um "tubo" para transmitir suas informações, ao invés de incorporá-la a sua prática pedagógica e não sofreu acoplamentos tecnológicos mesmo após três semestres ministrando o curso. A tarefa proposta gerou o envio de algumas mensagens (basicamente para troca de exercícios resolvidos), mas não propiciou o estabelecimento de uma efetiva rede de conversações, apesar dos alunos, neste momento, já demonstrarem domínio significativo da língua.

No segundo semestre de 2003, foram criadas novas turmas de outros idiomas (denominados aqui de Cursos de Línguas 2 e 3), que permitiram uma comparação entre as propostas pedagógicas dos professores e sua repercussão sobre as pautas comunicativas. Os professores responsáveis por estes cursos tinham alguma experiência com os recursos tecnológicos, mas nenhuma vivência em cursos a distância e, por este motivo, participaram de curso de formação específica antes do início das aulas, bem como foram acompanhados e monitorados ao longo de todo o curso. Durante o curso de formação, eles tiveram a oportunidade de conhecer o ambiente virtual de aprendizagem, primeiro como alunos e depois exercendo o papel de professores. Neste período, puderam discutir sobre as potencialidades do ambiente e explorar todos os recursos para apoio à comunicação, assistindo às aulas de outros professores e testando os recursos disponíveis, optando então por aqueles que mais condiziam com sua proposta de trabalho no curso de línguas.

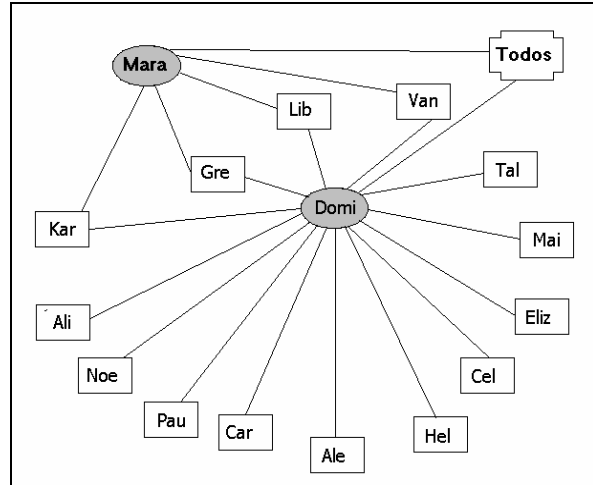

Figura 5 - Interações via correio no Curso de Línguas 2 
No Curso de Línguas 2 verificou-se a reprodução do modelo de ensino e aprendizagem adotado pelo Curso 1, onde o professor ministrava as aulas em tempo real via videoconferência e utilizava o ambiente virtual para publicação de material de apoio e atividades extraclasse (essencialmente exercícios a serem encaminhados ao professor para correção).

O mapa das interações (Figura 5) ocorridas através do correio eletrônico ao longo do curso mostra a centração das atividades no professor e nenhuma interação entre os alunos, dados estes confirmados pelo gráfico do número de mensagens, onde a curva que representa as mensagens enviadas pelo formador supera sempre a curva de mensagens dos alunos (Figura 6).

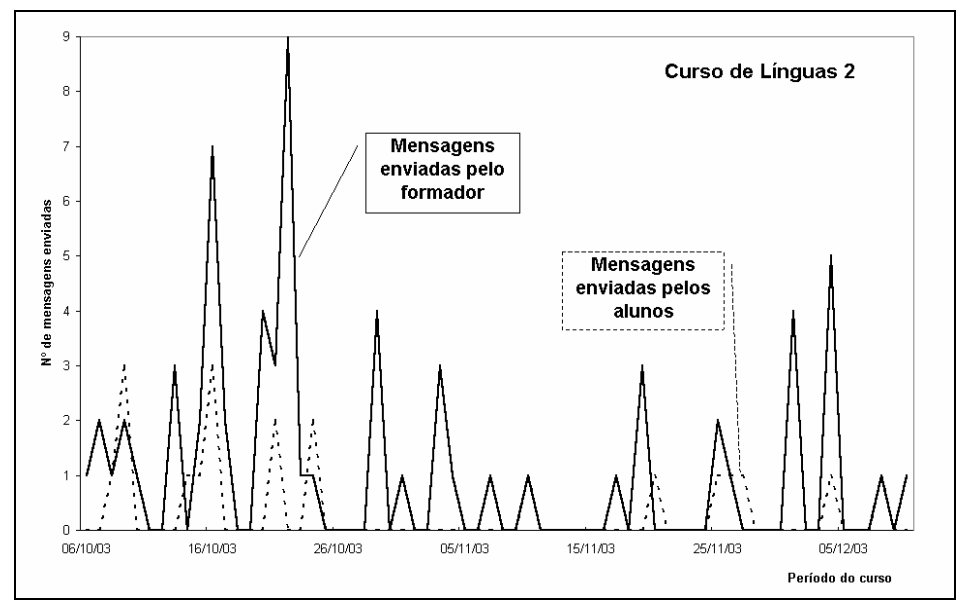

Figura 6 - Curso de Línguas 2 - mensagens enviadas no período

A análise do conteúdo das mensagens, no entanto, mostrou uma busca constante do professor de aproximação com seus alunos, incentivando-os a participar (e envolvendo o emocionar e o linguajar para constituir um conversar) e estabelecer uma rede de conversação. Para Maturana (CARNEIRO, 2003), o conversar é uma consequiência do entrelaçamento do linguajar e emocionar na convivência e o emocionar é que nos faz passar de um processo para o outro ou de um modelo de comunicação para o outro.

No entanto, como o registro das comunicações ocorridas parece demonstrar, a tecnologia aqui é ainda utilizada como um "tubo" para conectar um "emissor" e um "receptor", como no modelo tradicional para a comunicação proposto por Shannon (1948) e questionado por Maturana e Varela (2001) . Não é possível ainda detectar uma superação deste modelo tradicional de comunicação, onde os papéis parecem tão definidos, para uma visão da ecologia cognitiva, onde a díade emissor-receptor passa a ser exercida por qualquer participante, que pode ora ser emissor, ora receptor, ora interpretador, manipulador e autor da comunicação e da aprendizagem, numa relação todos-para-todos.

Numa visão autopoiética, não há como transmitir informações a alguém, mas sim gerar alguma perturbação para que este informação seja percebida, interpretada e transformada pelo sujeito. E aí abre-se o espaço para o trabalho do professor, que pode planejar atividades que gerem perturbações cognitivas e significativas em seus alunos. 
Atividades como a proposta pelos professores do Curso de Línguas 3, que sugeriram que os alunos apresentassem-se uns aos outros através do correio eletrônico do ambiente do curso, é um exemplo de como o trabalho do professor pode interferir e promover o estabelecimento de novos domínios cognitivos. Esta atividade simples desencadeou uma série de interações (na língua que estava sendo aprendida, entremeadas com palavras em português), entrelaçando o emocionar dos alunos (busca pelo colega distante, curiosidade por suas características e interesses, por ex.) com o seu linguajar, constituindo uma rede de conversações.
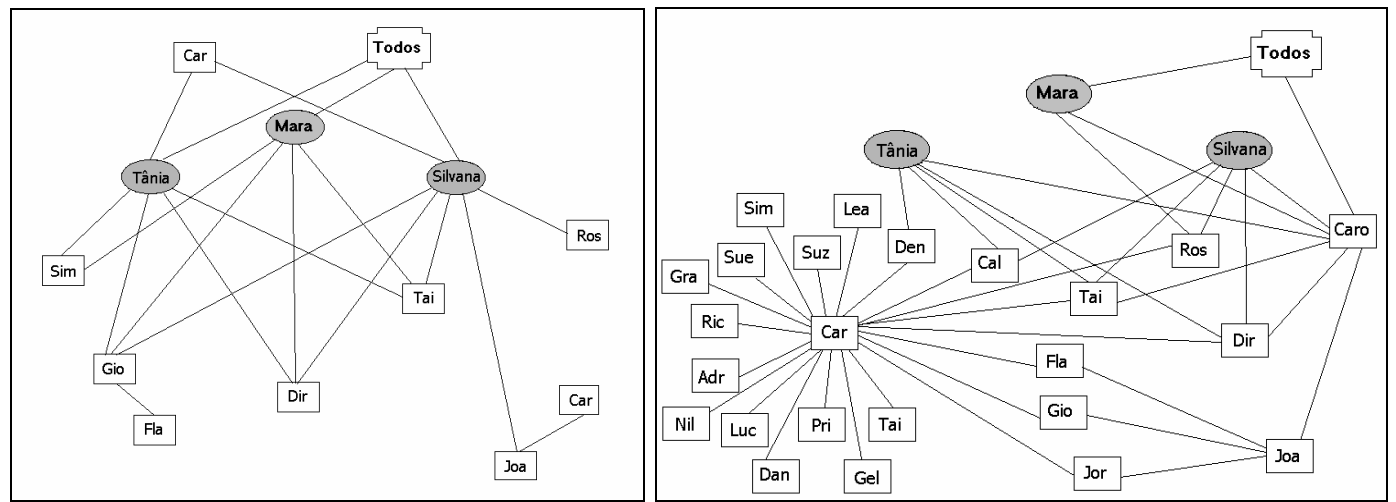

Figura 7 - Mapas das interações ocorridas no Curso de Línguas 3

A Figura 7 mostra dois momentos do curso (antes e depois da proposição da citada atividade), indicando o aumento do número de nós na rede bem como as trocas ocorridas. O gráfico do número de mensagens trocadas entre formador e alunos mostra uma oscilação constante ao longo do curso (Figura 8). Neste gráfico pode-se verificar que o número de mensagens enviadas pelos alunos (linha tracejada) supera o número de mensagens enviadas pelos professores (linhas contínua) em praticamente todo o período analisado. Este fato parece indicar que os professores participaram mais intensamente do processo interativo, mas não conduziram o processo.

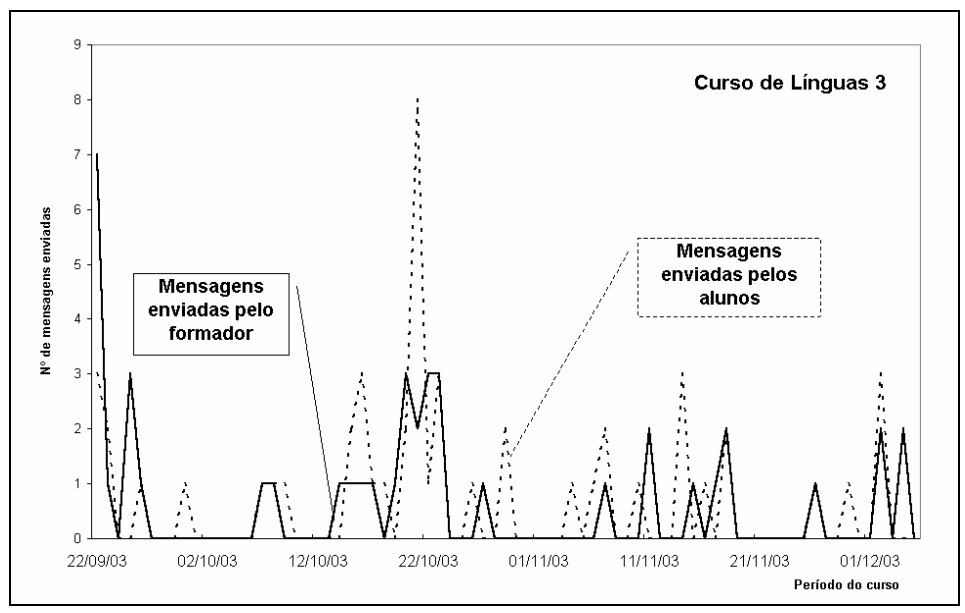

Figura 8-Mensagens trocadas entre formador e alunos no Curso de Línguas 3

Nos três cursos pode-se verificar que ainda há pouca exploração dos recursos tecnológicos que envolvem a comunicação assíncrona (como no caso do correio eletrônico) e que poderiam propiciar a instauração de domínios de aprendizagem. 


\section{E O PROFESSOR?}

Com o acompanhamento constante do trabalho dos professores envolvidos, pode-se verificar que somente um curso de formação não é suficiente para auxiliá-los nesta complexa tarefa de promover a aprendizagem em cursos a distância.

A palavra aprendizagem está associada ao ato de apreender, ou seja, captar algo. Mas, como destaca Maturana (2001b), a aprendizagem não é a captação do nada, mas sim o ato de transformar-se em um meio particular de interações recorrentes.

Ao criar um ambiente de aprendizagem (que pode incluir um ambiente acessado via Internet, videoconferência, etc.), o professor está estabelecendo um domínio social, um espaço possível de interação. No entanto, este domínio só passará a ser um domínio de aprendizagem se propiciar condições para que ocorram interações (através da linguagem) entre os participantes, permitindo que ocorram coordenações das ações e coordenações das coordenações de ações (meta-cognição).

A função básica da linguagem não é de transmitir informações ou descrições de um universo independente sobre o qual falamos, mas criar um domínio consensual de comportamento entre os sistemas que interagem lingüisticamente, através do desenvolvimento de domínios cooperativos de interações (MATURANA, 1970). E o estabelecimento destes domínios cooperativos dependem de como o professor se utiliza dos recursos tecnológicos. Quando os professores a consideram como um "canal" de comunicação, acabam por utilizá-la somente para enviar mensagens ou informações aos alunos, centrando o processo. Mas no momento em que a tecnologia passa a fazer parte do próprio ato comunicativo, acaba por produzir alterações na própria proposta pedagógica do professor (CARNEIRO, 2003).

\section{CONSIDERAÇÕES FINAIS}

A análise dos cursos a distância e outras experiências com a inclusão da tecnologia no processo educativo mostram que há ainda um longo caminho a trilhar. Não basta construir salas ricas em tecnologia, com computadores, acesso à Internet e recursos sofisticados como um sistema de videoconferência.

Há a necessidade também de pensar-se na formação dos professores e alunos para viverem neste novo mundo. Só uma maior conhecimento sobre as potencialidades dos recursos tecnológicos disponíveis poderá permitir que estes passem a constituir novos domínios de aprendizagem, com espaço para a interação e a cooperação.

\section{REFERÊNCIAS BIBLIOGRÁFICAS}

CARNEIRO, M.L.F. O acoplamento tecnológico e a comunicação em rede: inventando outros domínios de aprendizagem. 2003. 187p.. Tese (Doutorado em Informática na Educação) - Programa de Pós-Graduação em Informática na Educação, Universidade Federal do Rio Grande do Sul, Porto Alegre.

CARNEIRO, M.L.F. e MARASCHIN, C. Laboratório de Línguas a Distância na UERGS: a constituição de novos domínios de aprendizagem. RENOTE - Revista Novas Tecnologias na Educação. v.1. n.1. fev, 2003. Disponível em: <http://www.cinted.ufrgs.br/renote/fev2003/artigos/maral_laboratorio.pdf>. Acesso em: 10 fev. 2004. 
MATURANA, H. Biology of Cognition. Biological Computer Laboratory Research Report BCL 9.0. Urbana IL: University of Illinois, 1970. Disponível em: <http://www.enogaia.com/M70-80BoC.html.>. Acesso em 12 fev 2004. . A ontologia da realidade. Belo Horizonte, Editora da UFMG, 2001. $2001 \mathrm{~b}$. Cognição, Ciência e Vida Cotidiana . Belo Horizonte: Editora da UFMG,

MATURANA, H. e VARELA, F. A árvore do conhecimento: as bases biológicas da compreensão humana. São Paulo, Palas Athena, 2001.

ROCHA, H. O ambiente TelEduc para a educação a distância baseada na Web: princípios, funcionalidades e perspectivas em desenvolvimento. In: MORAES, C. Educação a distância: fundamentos e práticas. Campinas, UNICAMP/NIED, 2002.

SHANNON, C.E. A Mathematical Theory of Communication. The Bell System Technical Journal, Vol. 27, pp. 379-423, 623-656, July, October, 1948. Disponível em: $<$ http://cm.bell-labs.com/cm/ms/what/shannonday/shannon1948.pdf $>$. Acesso em 08 fev 2004. 